\title{
Contribuições da monitoria acadêmica em Centro Cirúrgico para o processo de ensino-aprendizagem: benefícios ao monitor e ao ensino
}

Contribution of academic tutoring for the teaching-learning process to teaching experience in surgical center: the benefits to instructor and education

Contribución de la tutoría académica para el proceso enseñanza-aprendizaje en el centro quirúrgico: beneficios para el monitor y para la enseñanza

Francisco Lucas de Lima Fontes ${ }^{1 *}$, Mayara Macedo Melo ${ }^{1}$, Josélia Costa Soares ${ }^{1}$, Julia Maria dos Santos $^{1}$, Cynthia Araújo Frota ${ }^{1}$, Ana Raquel Freitas dos Santos ${ }^{1}$, Lídia Viana Araújo ${ }^{1}$, Wesley Brandolee Bezerra Fernandes ${ }^{1}$, Nayra lolanda de Oliveira Silva1', Dulcimar Ribeiro de Matos ${ }^{1}$, Ywsnara Khysnna da Silva Viveiros ${ }^{1}$, Martha Teixeira do Nascimento ${ }^{1}$, Francisca Jéssica Abreu da Silva ${ }^{1}$, Telma Costa da Silva ${ }^{1}$, Andressa Maria Lima Sousa'1.

\section{RESUMO}

Objetivo: Relatar a experiência da monitoria acadêmica em centro cirúrgico para o processo de formação docente. Relato de experiência: Coube à monitoria preparar o aluno para o entendimento mais claro acerca da montagem do kit cirúrgico básico menor e explicação dos instrumentais cirúrgicos, bem como sanar possíveis dúvidas sobre os variados conteúdos teórico-práticos ofertados na disciplina, com vistas a facilitar o processo de ensino-aprendizagem. Os acadêmicos puderam vivenciar as atividades, a dinâmica e as técnicas básicas praticadas no centro cirúrgico. Conclusão: A presença de monitor na disciplina permite a retirada de dúvidas pelos alunos, tendo em vista que, estes, veem o monitor como um aluno que vivenciou as mesmas dificuldades anteriormente. Fica clara a importância da monitoria de laboratório sobre atividades realizadas em centro cirúrgico, considerando que o auxílio é estimulante para o exercício de boas práticas nos estágios.

Palavras-chave: Educação em Enfermagem, Centro cirúrgico, Ensino, Aprendizagem.

\begin{abstract}
Objective: To report the experience of the academic monitoring of surgical center for the process of teaching training. Experience report: It was up to the monitor to prepare the student for the clearest understanding about the assembly of the minor basic surgical kit and explanation of the surgical instruments, as well as to answer possible doubts about the varied theoretical-practical contents offered in the discipline, with a view to facilitating the teaching-learning process. The academics were able to experience the activities, dynamics and basic techniques practiced in the surgical center. Conclusion: The presence of a monitor in the discipline allows the students to withdraw doubts, considering that, these, see the monitor as a student who experienced the same difficulties previously. It is clear the importance of laboratory monitoring on activities performed in Surgical Center, considering that the aid is stimulating for the practice of good practices in the stages.
\end{abstract}

Keywords: Nursing education, Surgicenter, Teaching, Learning.

${ }^{1}$ Faculdade UNINASSAU - Campus Redenção. Teresina, Piauí, Brasil. *E-mail: lucasfontesenf@hotmail.com SUBMETIDO EM: 5/2019 


\section{RESUMEN}

Objetivo: Informar la experiencia de la monitoría académica en el centro quirúrgico para el proceso de formación docente. Relato de experiencia: Corresponde a la monitoria preparar al alumno para el entendimiento más claro acerca del montaje del kit quirúrgico básico menor y explicación de los instrumentales quirúrgicos, así como sanar posibles dudas sobre los variados contenidos teórico-prácticos ofrecidos en la disciplina, con miras a facilitar el aprendizaje proceso de enseñanza-aprendizaje. Los académicos pudieron vivenciar las actividades, la dinámica y las técnicas básicas practicadas en el centro quirúrgico. Conclusión: La presencia de monitor en la disciplina permite la retirada de dudas por los alumnos, teniendo en vista que, éstos, ven el monitor como un alumno que experimentó las mismas dificultades anteriormente. Es evidente la importancia del monitoreo de laboratorio sobre actividades realizadas en centro quirúrgico, considerando que la ayuda es estimulante para el ejercicio de buenas prácticas en las etapas.

Palabras-clave: Educación en Enfermería, Centro quirúrgico, Enseñanza, Aprendizaje.

\section{INTRODUÇÃO}

A monitoria acadêmica é um serviço de apoio pedagógico encarregado de sanar dificuldades relacionadas à disciplina trabalhada em aula, possibilitando aos alunos oportunidade de aprofundar conhecimentos (HAAG GS et al., 2008). Com ela, cria-se uma melhor correlação teórico-prática ao viabilizar, em meio ao processo de ensino-aprendizagem, a autonomia para o aluno questionar, praticar e revisar conteúdos aplicados em sala, diminuindo incertezas e ampliando confiança quanto aos conteúdos vistos (CARVALHO IS et al., 2012).

A Lei № 9.394, de 20 de dezembro de 1996, determina as diretrizes e bases da educação nacional. Em seu artigo 84, a referida lei delibera que "os discentes da educação superior poderão ser aproveitados em tarefas de ensino e pesquisa pelas respectivas instituições, exercendo funções de monitoria, de acordo com seu rendimento e seu plano de estudos". Segundo Schneider MSPS (2006), a monitoria pode ser entendida como um recurso formativo de ensino que possui como finalidades: nortear discentes na construção de conhecimento da disciplina proposta; possibilitar a promoção de aprimoramento das competências pedagógicas; garantir ao discente-monitor a vivência do trabalho pedagógico com supervisão do docente.

O discente-monitor é o acadêmico motivado pelo autodesenvolvimento que une-se a uma disciplina ou área de conhecimento, realizando ações que contribuam para o ensino, a pesquisa e a extensão. Quanto mais o monitor vivencia a condição de acadêmico na mesma disciplina, mais sensível torna-se na percepção de prováveis dificuldades de conteúdo, conseguindo auxiliar o aluno na solução de problemas encontrados. Essa dinâmica promove o estreitamento de vínculo com a realidade docente e o desenvolvimento das práticas pedagógicas (ALMEIDA RS et al., 2016).

Durante sua atuação, aprimora seus próprios conhecimentos ao passo em que se envolve com atividades pedagógicas. Tal prática beneficia o preenchimento de lacunas na vida acadêmica, proporcionando criação de vínculos com a academia, com a docência e com questões educacionais (ABREU TO et al., 2014).

Para Fernandes $\mathrm{J}$ et al. (2016), este ao realizar o trabalho docente de maneira amadora, experimenta os desafios e dificuldades do "ser docente universitário" no decorrer do programa de monitoria. Ao entrar em contato direto com discentes estando simultaneamente também como aluno, possibilita a ampliação de conhecimento e prazer em colaborar pedagogicamente com o aprendizado de acadêmicos. Diante do que foi introduzido, o objetivo do presente estudo foi relatar a experiência da monitoria acadêmica de centro cirúrgico para o processo de formação docente.

\section{RELATO DE EXPERIÊNCIA}

A experiência foi vivenciada por meio da monitoria acadêmica da disciplina de "Cuidado Integral ao Paciente Cirúrgico" I e II do curso bacharelado em Enfermagem de uma instituição de ensino superior privada de Teresina, capital do Piauí. Esta era ofertada aos alunos no quinto e sexto período da graduação, 
respectivamente. Tal experiência ocorreu nos dois semestres de 2017, quando os autores-monitores deste estudo ainda se encontravam na graduação.

Essa disciplina tem como objetivos discriminar as etapas da instrumentação cirúrgica; reconhecer e distinguir os principais instrumentais cirúrgicos; executar a Sistematização da Assistência de Enfermagem Perioperatória (SAEP) ao paciente nos períodos pré, trans e pós-operatório de cirurgias em geral; cuidado de Enfermagem nos diversos tipos de cirurgias; planejamento e execução do cuidado de Enfermagem ao adulto em condições cirúrgicas, incluindo preparo para a alta e assistência no domicílio; noções de anestesiologia; métodos de antissepsia, assepsia e esterilização; estrutura e funcionamento do centro cirúrgico, centro de material e esterilização e sala de recuperação pós-anestésica; processo de esterilização dos materiais; e noções de instrumentação cirúrgica, sendo esta última competência o foco central deste relato.

Com carga horária teórica e prática, 100 horas em sala e 40 horas no laboratório, a disciplina foi ministrada por uma enfermeira docente com ênfase em Saúde Pública e larga experiência na área cirúrgica. As aulas práticas eram realizadas em laboratório e unidades hospitalares.

O plano de ação foi desenvolvido no laboratório de Enfermagem da instituição, pelas práticas de monitoria da disciplina. Coube à monitoria preparar o aluno para o entendimento mais claro acerca da montagem do kit cirúrgico básico menor e explicação dos instrumentais cirúrgicos, bem como sanar possíveis dúvidas sobre os variados conteúdos teórico-práticos ofertados na disciplina, com vistas a facilitar o processo de ensinoaprendizagem. No local, os acadêmicos puderam vivenciar as atividades, a dinâmica e as técnicas básicas praticadas no centro cirúrgico.

Durante a monitoria, foram empregadas algumas estratégias para que as práticas ocorressem de maneira eficiente e contínua, com atividades que podem ser vistas conforme explicitado no Quadro 1.

Quadro 1 - Atividades desenvolvidas na monitoria de "Cuidado Integral ao Paciente Cirúrgico" I e II.

\begin{tabular}{|l|}
\hline 1. Acompanhamento das práticas em laboratório \\
\hline 2. Orientação e esclarecimento de dúvidas \\
\hline 3. Organização dos materiais de laboratório para realização das aulas práticas \\
\hline 4. Aplicação da prova prática, no auxílio à enfermeira docente \\
\hline 5. Participação na confecção do material de apoio aos estudos \\
\hline 6. Registro da frequência dos atendimentos aos discentes e posterior encaminhamento à enfermeira docente \\
\hline 7. Participação também nas aulas teóricas da enfermeira docente, exercendo funções de monitoria em sala \\
\hline
\end{tabular}

Fonte: Próprios autores (2019).

A prática era realizada em cinco segmentos distintos: lavagem e degermação das mãos, paramentação cirúrgica, colocação de luvas estéreis, organização e explicação do kit cirúrgico básico menor e dobragem do capote.

Na lavagem das mãos era apenas relembrada a técnica correta de higienização das mãos, uma vez que esse procedimento foi visto na disciplina de Semiotécnica, presente no quarto período do curso. No centro cirúrgico, além da lavagem das mãos, também faz-se necessária a lavagem dos antebraços, visando reduzir assim a propagação de microrganismos durante o ato cirúrgico.

Os discentes tiveram a oportunidade de entender a importância de tal ato na prevenção de infecção de sítio cirúrgico, bem como compreender a técnica correta para degermar mãos e antebraços com utilização da escova-esponja.

Na paramentação cirúrgica os acadêmicos puderam visualizar a maneira correta de vestir o avental/capote estéril utilizando técnica asséptica, a fim de não o contaminar. Para tal, é necessária ajuda de um auxiliar, onde em centro cirúrgico esta função é exercida pelo circulante. Assim como na lavagem das mãos, o calçamento de luvas estéreis também foi relembrando e praticado em laboratório, destacando-se que a forma de colocação das luvas estéreis segue princípios assépticos, diferente das habituais luvas de procedimento. 
Na montagem e explicação do kit cirúrgico básico menor, os alunos compreenderam que a cirurgia é dividida em quatro tempos distintos, sendo eles diérese, hemostasia, exérese e síntese, e que antes de adentrar nos tempos, tem-se o momento de antissepsia do local que será operado.

O tempo de diérese é o tempo de corte, é o momento em que é feita a incisão cirúrgica, permitindo a exposição de órgãos e estruturas afetadas. Na hemostasia, há a contenção de sangramento através do pinçamento de vasos sangrantes. A exérese é o tempo de retirada de órgão, tecido ou corpo estranho, este tempo está ausente em algumas cirurgias, pois nem todo procedimento cirúrgico terá retirada de órgão, tecido ou corpo estranho.

O tempo de síntese é o momento em que é feita a sutura, o tempo de fecho cirúrgico. Além dos instrumentos utilizados em cada tempo cirúrgico, existem peças auxiliares úteis na realização de alguma intervenção de maneira coadjuvante. Foram exibidos e explicados aos alunos os instrumentais utilizados em cada tempo cirúrgico, bem como sua função e correta disposição destes na mesa cirúrgica.

Os alunos foram orientados também quanto à dobradura do capote/avental cirúrgico. É importante lembrar que após a utilização do capote/avental com o término da cirurgia, ele é desprezado no hamper e encaminhado à central de material esterilizado para que lá ocorra a devida limpeza e posteriormente dobradura antes de ser encaminhado para esterilização. Contudo, a título de conhecimento eles tiveram que assimilar a correta técnica de dobra do capote/avental.

\section{DISCUSSÃO}

O centro cirúrgico é um setor hospitalar que abrange espaços e instalações que possibilitam a execução de procedimentos cirúrgicos nas máximas circunstâncias de segurança ao paciente e de proteção à equipe que $\mathrm{o}$ atende. É tido como um setor extremamente complexo, monitorado com exigentes padrões de higiene e assepsia (SALES DRC et al., 2010).

Devido a invisibilidade dos procedimentos executados e a resultante redução das defesas do organismo, este setor e as atividades desenvolvidas nele tornam-se importante razão ao surgimento de infecções relacionadas à assistência à saúde (OLIVEIRA AC e GAMA CS, 2015).

Essas infecções refletem um grave problema de saúde pública, podendo ser adquiridas durante à assistência à saúde, antes ou após a alta. Dentro desse contexto, evidenciam-se as infecções de sítio cirúrgico, manifestando-se de 30 a 90 dias após o ato cirúrgico.

Esse tipo de complicação repercute negativamente na vida do paciente, ocasiona sérios danos, inclusive o óbito, quando não implementadas ações terapêuticas. Condutas simples como higienização e degermação das mãos, utilização de luvas estéreis e paramentação adequada são medidas essenciais para prevenção destes agravos (BARRETO RASS et al., 2012).

Lavar as mãos com antisséptico (antimicrobiano) é indicado em determinados ambientes de cuidados de saúde, como o centro cirúrgico, onde a equipe cirúrgica deve realizá-la antes de todo e qualquer procedimento. Este ato reduz de forma drástica a contagem bacteriana nas mãos, constantemente tendo efeito residual de várias horas (PERRY AG et al., 2013).

No centro cirúrgico, além da lavagem, também deve ocorrer degermação de mãos e antebraços. Na degermação várias são as substâncias indicadas, como iodos formulados com detergente aniônico ou clorexidina a $2 \%$, com auxílio de escovas apropriadas. O uso de antissépticos é recomendado a toda a equipe que presta assistência na sala de operação durante o ato cirúrgico (DOTTO PP et al., 2015).

A utilização de luvas estéreis é tida como ação complementar à antissepsia cirúrgica das mãos, visto que atuam como barreiras aos microrganismos, embora não sejam capazes de eliminá-los, são imprescindíveis à segurança do profissional e dos pacientes (OLIVEIRA AC e GAMA CS, 2016).

Quando há necessidade de auxílio no campo estéril de uma sala de operação, é importante a utilização do avental/capote estéril. O capote estéril permite ao profissional manusear objetos também estéreis e estar 
confortável em relação ao menor risco de contaminação. O capote somente deverá ser vestido após lavagem e degermação das mãos e colocação da máscara e touca cirúrgica (POTTER PA et al., 2013).

O campo estéril, como componente da paramentação cirúrgica, é aquele tecido que permanece sobre o paciente nos territórios adjacentes do sítio cirúrgico. Boa parte desses campos são confeccionados em tecidos de algodão e no Brasil são amplamente utilizados. Campos descartáveis também são viáveis e possuem como diferenciais a impermeabilidade a líquidos, microrganismos e partículas, permissão de trocas gasosas para manutenção das condições normais da pele e baixo risco de contaminação, pois só é utilizado uma única vez. A paramentação é composta por capote estéril, campos, gorro, máscara, propés e luvas, que devem ser usadas por todos os profissionais da equipe cirúrgica que participam do procedimento cirúrgico (OLIVEIRA AC e SILVA MVG, 2015).

É essencial organização durante o ato cirúrgico. Para tal, a mesa de instrumentação deve dispor de maneira sistemática os utensílios empregados em cada tempo cirúrgico. Para exposição dos instrumentais, divide-se a mesa cirúrgica por quadrantes, para comportar os instrumentais de cada tempo cirúrgico. Essa organização facilita o andamento do procedimento cirúrgico e padroniza as ações do instrumentador, portanto dando mais precisão à sequência cirúrgica (MORIYA T et al., 2011).

A experiência de ser monitor oportunizou momentos de reflexão acerca das estratégias empregadas para incentivar acadêmicos a aprofundarem e revisarem conteúdos trabalhados na disciplina. Partindo do pressuposto de que o conhecimento é construído e não repassado, percebeu-se que os alunos sentiram-se desafiados a desenvolverem competências para atuação em centro cirúrgico, fortalecendo habilidades, confiança, organização, planejamento e responsabilidade nos estudos. A experiência também criou caminhos para novas compreensões sobre o processo de formação do graduando, ao proporcionar o acompanhamento das aulas práticas e promover espaço de diálogo entre monitores e docente, estreitando assim vínculos com as atividades desempenhadas no ensino.

\section{CONCLUSÃO}

Ressalta-se com este relato a importância das atividades de monitoria para o aprimoramento de habilidades técnicas como manuseio e compreensão de materiais e instrumentais, importantes na dinâmica do centro cirúrgico. A oportunidade de revisão de conteúdos ministrados em sala de aula, a aproximação com o ensino e o relacionamento positivo com os alunos matriculados na disciplina servem para despertar o interesse pela docência e favorece novas percepções acadêmicas. Cabe destacar que as funções desenvolvidas na monitoria permitem uma concepção mais real e palpável do centro cirúrgico, expandindo o conhecimento de alunos sobre o setor e as ações desenvolvidas nele. A experiência proporcionou crescimento acadêmico e pessoal, oportunizando o compartilhamento de saberes monitores-alunos e alunosmonitores, o desenvolvimento de habilidades e a contribuição para o ensino e formação acadêmica. A presença de monitor na disciplina permite a retirada de dúvidas pelos alunos, tendo em vista que, estes, veem o monitor como um aluno que vivenciou as mesmas dificuldades anteriormente. Fica clara a importância da monitoria de laboratório sobre atividades realizadas em centro cirúrgico, considerando que o auxílio é estimulante para o exercício de boas práticas nos estágios.

\section{REFERÊNCIAS}

1. ABREU TO et al. A monitoria acadêmica na percepção dos graduandos de enfermagem. Revista de Enfermagem da UERJ, 2014; 22(4): 507-512.

2. ALMEIDA RS et al. Contribuições da monitoria em elementos de anatomia para a formação acadêmica do aluno de psicologia: um relato de experiência. Cadernos de Graduação, 2016; 3(3): 169-180.

3. BARRETO RASS et al. A antissepsia cirúrgica das mãos no cotidiano de um Centro Cirúrgico. Saúde, 2012; 38(2): 9-16.

4. BRASIL. Ministério da Educação. Lei no 9.394, de 20 de dezembro de 1996. Estabelece as diretrizes e bases da educação nacional. Diário Oficial da União, Brasília, 1996. 
5. CARVALHO IS et al. Monitoria em Semiologia e Semiotécnica para a Enfermagem: um relato de experiência. Revista de Enfermagem da UFSM, 2012; 2(2): 264-271.

6. DOTTO PP et al. Eficácia de dois métodos de degermação das mãos. Revista de Cirurgia Traumatológica Bucomaxilo-facial 2015; 15(3): 7-14.

7. FERNANDES J et al. Influência da monitoria acadêmica no processo de ensino e aprendizagem da Psicologia. Clínica \& Cultura, 2016; 2(1): 36-43.

8. HAAG GS et al. Contribuições da monitoria no processo ensino-aprendizagem em enfermagem. Revista Brasileira de Enfermagem, 2008; 61(2): 215-220.

9. MORIYA T et al. Instrumental cirúrgico. Medicina, 2011; 44(1): 18-32.

10. OLIVEIRA AC, GAMA CS. Avaliação da adesão às medidas para a prevenção de infecções do sítio cirúrgico pela equipe cirúrgica. Revista Escola de Enfermagem da USP, 2015; 49(5): 767-774.

11. OLIVEIRA AC, SILVA MVG. Teoria e Prática na Prevenção da Infecção do Sítio Cirúrgico. 1a ed, Manole: Barueri, 2015.

12. POTTER PA et al. Fundamentos de Enfermagem. 8ª ed, Elsevier: Rio de Janeiro, 2013.

13. PERRY AG et al. Procedimentos e intervenções de Enfermagem. 5aㅡ ed, Elsevier: Rio de Janeiro, 2013.

14. SALES DRC et al. Concepções dos profissionais de enfermagem de uma unidade de centro cirúrgico sobre infecção hospitalar e lavagem de mãos antes e após a aplicação de uma atividade educativa. Revista Digital FAPAM, 2010; 2(2): 99-109.

15. SCHNEIDER MSPS. Monitoria: instrumento para trabalhar com a diversidade de conhecimento em sala de aula. Revista Espaço Acadêmico, 2006; 6(5): 65. 